\title{
Introductory Course Content Targeting Innovation and Entrepreneurship for Engineering Students
}

\section{Prof. Nihad Dukhan PhD, University of Detroit Mercy}

Professor Dukhan is an Associate Professor of Mechanical Engineering at the University of Detroit Mercy, where he teaches courses in the thermal and fluids sciences. His pedagogical research includes teaching and learning heat transfer and thermodynamics, as well as service learning. His technical research areas include novel thermal management solutions for high-power devices, with focus on fluid flow and convection heat transfer in metal foam. Professor Dukhan's publications include over 90 journal and conference papers. His edited book on metal foam, November 2012, is the most recent book about metal foams including their production, characterization and applications. His research has been supported by Ford Motor Company, NASA, National Science Foundation, United Technologies and DENSO North America. Dr. Dukhan earned his Ph.D. in 1996 in Mechanical Engineering from the University of Toledo, and has worked for the industry for 4 years. He is the recipient of the University of Detroit Mercy's Faculty Achievement Award for 2011.

Prof. Nassif E Rayess, University of Detroit Mercy 


\title{
Introductory Course Content Targeting Innovation and Entrepreneurship for Engineering Students
}

\begin{abstract}
The paper is about how a US university was able to implement content in an especially-designed engineering course to bring about awareness by engineering students of the critical and current topics of innovation and entrepreneurship. The need for such an awareness is specifically stressed by key organizations such as the National Academy of Engineers (NAE) and the Accreditation Board for Engineering and Technology (ABET). The course that housed th content was especially designed to target other issues in which innovation and entrepreneurship fit in, e.g., the nature of the knowledge-based economy, characterized by huge and rapid technological leaps and its effects on the engineering profession. The nature and need for innovation, the various kinds and advantages of entrepreneurship and business models associated with it were included. Other parts of the course covered complimentary topics to innovation and entrepreneurship such as working in teams and self-awareness in today's professional environment. Exercises affecting the ability to formulate and conduct a debate concerning innovative engineering concepts were part of the course. This paper describes the course design, content and rubric that were used to assess the course outcomes regarding innovation and entrepreneurship, as well as the results of the summative self-assessment of the students. In general, the results show that the vast majority of students agreed that the course had been effective is teaching and making them aware of the two critical contemporary issues, innovation and entrepreneurship, for the graduating engineers.
\end{abstract}




\section{Introduction}

The information age and the knowledge-based economy have a profound impact on engineering as a profession and on the way it is taught. Another wave of factors that are extremely critical in shaping the engineering profession are the rapidly changing technology, corporate downsizing, out-sourcing and globalization, growing population, looming energy shortages, health, security and environmental problems. These have called for changes in engineering curricula to prepare engineers for the future.

Realizing these facts, many engineering, education and governmental agencies, such as the Accreditation Board for Engineering and Technology (ABET), National Academy of Engineering (NAE), American Society of Mechanical Engineers (ASME) and the American Society of Engineering Education (ASEE), all point at the increasing importance of the nonetechnical skills (sometimes referred to soft skills) of graduating engineering. Such skills that allow graduates to comprehend the complex interdependence between engineering as a profession and society were referred to as 'contextual competence'.

In the new ABET criteria, there is a clear emphasis on these skills. ${ }^{2}$ The criteria say that skills in communication, persuasion, teamwork and understanding of the non-technical factors that affect engineering decisions are all indispensable for the engineers of the future. Under Criterion 3 titled Program Outcomes and Assessment, item (h), it says that the students must have "the broad education necessary to understand the impact of engineering solutions in a global, economic, environmental, and societal context"; and under item (j), it says students must have "knowledge of contemporary issues." 2

One source refers to the ABET set of six non-technical skills as the professional skills and divides them into two types: process skills which include communication skills, teamwork and understanding ethics and professionalism, and awareness skills which include engineering within a global and societal context, lifelong learning and knowledge of contemporary issues. ${ }^{3}$. It also states that some of these skills can certainly be taught and assessed. ${ }^{3}$

NAE says that the engineer of 2020 is a person with strong communication skills, and that the engineers will have to deal with interdisciplinary and globally diverse teams, public officials and a global customer base. ${ }^{4}$ In its report titled The Engineer of 2020: Visions of Engineering in the New Century, NAE says: “.... It is our aspiration that engineers will continue to be leaders in the movement toward use of wise, informed, and economical sustainable development. This should begin in our educational institutions.",

One of the current topics in engineering is innovation, which has emerged as a critical factor in today's economy, especially as a way to win in the highly competitive environment. The National Academies have issued a report titled Rising to the Challenges: U.S. Innovation Policy for the Global Economy. This report points to a number of troubling trends in a range of U.S. competitiveness indicators-mainly due to lack of innovation. The report states: "in an era of rapid growth in new knowledge that is being generated around the world, the United States should cooperate more actively with other nations to advance innovations that address shared global challenges in energy, health, the environment and security."5 
A recent extensive ASEE report titled "Innovation with Impact: Creating a Culture and Systematic Innovation in Engineering Education," offers a guide for changing the engineering education culture such that engineering programs are more engaging and relevant though entrepreneurial, international and other experiences that are personally rewarding, current and are designed to help students success in today's economy. ${ }^{6}$

Undergraduate engineering education is at a crossroad. The Royal Academy of Engineers indicated that there has been a broad consensus that traditional undergraduate programs are not equipping graduates with the skills needed for the complex challenges of the twenty-first century. ${ }^{7}$ Most traditional engineering programs focus on technical development, rather than on preparing socially responsible engineers with a strong sense of citizenship who are prepared to work in complex communities. ${ }^{8}$

The American Society of Mechanical Engineers (ASME) has formed Vision 2030 Task Force from young engineers, educators and industrial managers to assess the preparation of engineers in key skill areas. Managers indicated that young engineers lack in interpersonal team work, communication skills within diverse engineering teams and with non-engineers in a given organization, system perspective and knowledge of business processes. ${ }^{9}$ The report also recommended emphasis on innovation, leadership, and entrepreneurship.

The case for reforming our engineering educational system has been made. The challenge has been how to make the needed change happen in the curriculum. New practices in teaching such as inquiry- and project-based learning, experiential learning, and service learning ${ }^{10}$ as a way for learning non-technical skills are now common.

New changes in curricula and/or extra requirements from students can put pressure on the already-packed engineering curriculum. The reform effort of the department of civil and environmental engineering at University of Vermont, described above, developed a series of three system courses to implement the reform. Students were displeased about the organization of the newly designed systems courses. ${ }^{11}$ Some too-ambitious curriculum reform efforts have failed. ${ }^{7}$

There is a need for surgically implementing non-technical skills components in the alreadystrained engineering curricula. The current paper describes in some detail the design and implementation of a course that has targeted few of the non-technical skills needed for the engineers of today and the future, especially the awareness of the need for innovation and entrepreneurship and skills needed to support such activities. It also provides a general students' perception of the impact of the course on the development of some of the participating students' attitudes and awareness. Hence, this paper may be used as example that can help some engineering faculty and departments in implementing such components in engineering curricula.

\section{Course Description}

\subsection{Objective and Outcomes}

The course focuses on enhancing student's understanding of major issues that impact the engineering profession, and on improving their non-technical skills and ability to form 
judgments based on literature analysis and available data. The course formal objectives were to develop the engineering student as a professional able to better engage and address the ethical, global, political and social issues of engineering using logical and informed judgment.

The course design was guided by input from the engineering employers in the industry through the department of mechanical engineering's Industry Advisory Board, which meets with the faculty and makes recommendations to the department on the skills that are expected form graduating engineers. The department also has funding geared toward implementing innovation and creativity into the curriculum, and continuous efforts in entrepreneurship.

The course outcomes were listed as follows. After taking this course, students will have an:

1. increased ability to evaluate contemporary issues of the engineering profession

2. increased ability to evaluate professional and ethical responsibility

3. increased ability to evaluate the impact of engineering solutions in a global, social context

4. increased ability to evaluate the importance of team work

5. increased ability to make judgments based on analysis of literature and of existing data

6. increased ability to engage in life-long learning (and recognition of the need to do so)

7. increased ability to make an effective presentation both in written and oral format

The course has been required for all engineering students at the University of Detroit Mercy, and is usually taken in their sophomore year. The name of the one-credit-hour semester course has been Professional World of Work (PWOW). It has been meeting once a week for 50 minutes. The course is different from typical instructions in the sense that engineering students had to do a lot of non-technical reading, reflect on their own learning and on the world conditions around them, participate in group discussions, integrate their new knowledge and non-technical skills in brainstorming, debating, proposing and making business and technical cases for designs of new engineered products.

\subsection{Materials and Delivery}

The course instructor presented most of the topics covered in the course, assigned reading materials for each topic, typically once a week. After each reading, the students took a short quiz, after which the instructor engaged in open discussions of each topic. Students were encouraged to reflect and critically think about the knowledge and opinions presented in the reading materials. In this manner, students were repeatedly exposed to each topic in these various ways. The authors contend that these multiple exposures were likely effective in bringing about awareness of the topics. The following topics and reading materials were covered:

- Awareness of changing landscape: Managing oneself in a knowledge-based economy ${ }^{12}$

- Entrepreneurship and business models for social entrepreneurship ${ }^{13}$

- Innovation

Students' averages in the quizzes were very good, indicated that they did the reading and absorbed the materials. As a good portion of the course relied on reading by students, nonnative speakers of English (Chinese students) scored a little lower in the quizzes. 
Some topics were delivered by speakers who were professors that had an extensive industry experience, and were less tied to how things are usually taught in the university. Such speakers incorporate authentic engineering experiences into the curriculum.

\section{Impact on Students' Awareness}

\subsection{Students Survey}

Student had to respond to the questions in a questionnaire that was administered to them at the end of the course by the department's chair. Students had to indicate their level of agreement to each statement in the questionnaire. Namely students had to choose one of the following responses: Strongly agree, Agree, Slightly agree, Disagree or Strongly disagree. Nineteen students responded to the questionnaire and responded to the following questions:

1. Entrepreneurship, innovation and the need for continued self-education are important issues for the engineering profession today.

2. Some of the assignments in this course helped you realize the value of these important issues.

3. Entrepreneurial mindedness enables engineers to stay ahead of, or even drive the rapid technological changes rather than struggle or simply adapt to them.

4. Pushing innovative ideas through corporate entrepreneurship requires a deep understanding of corporate culture and business processes.

5. As a result of taking this course, you have become aware of various aspects of corporate entrepreneurship.

6. Social entrepreneurship is a relatively new set of business models in which entrepreneurs step in to fill the gap where governments are not able or willing to provide a public good, and where the private sector cannot justify the risk involved.

7. As a result of taking this course, you have acquired some familiarity with the prevalent business models within social entrepreneurship, and how it can be a career path.

8. Knowing oneself (strengths, the way one works, and one's values) are critical to the success of engineers in today's economy.

9. Some of the assignments in this course helped you realize the value of these important issues.

10. Very few people work by themselves. Most people work with others, and are effective with others. To be effective working with other people, you need to know their performance modes, their strengths and their values.

It should be noted that the course included other activities targeting the other stated outcomes of the course. These activities are not assessed in this paper.

\subsection{Students' Responses}

The last offering of the course had 20 students from civil, mechanical and electrical engineering. This number is typical. University of Detroit Mercy is a small Catholic university. The last cohort had four female students and four Chinese students. There were two Hispanic students 
and two African American students. The rest of the class was white students. Students' responses to the eight questions were collected and analyzed to identify general trends, and to gauge students' awareness and the effectiveness of the course in bringing about their awareness.

Questions 1 and 2 probed students' awareness of three important contemporary issues for the today's engineering profession: entrepreneurship, innovation and the need for continued selfeducation. Figure 1 displays the responses of students to these two questions. The columns in blue are for question 1, while the dark red columns are for question 2 . The responses to question 2 gauge the effect of the course materials on students' awareness of entrepreneurship, innovation and continued self-education. A slight majority of students (58\%) either strongly agreed or agreed that the course has helped them in this regard. A group of students (37\%) slightly agreed that the course helped them, while only one student disagreed that the course provided any help.

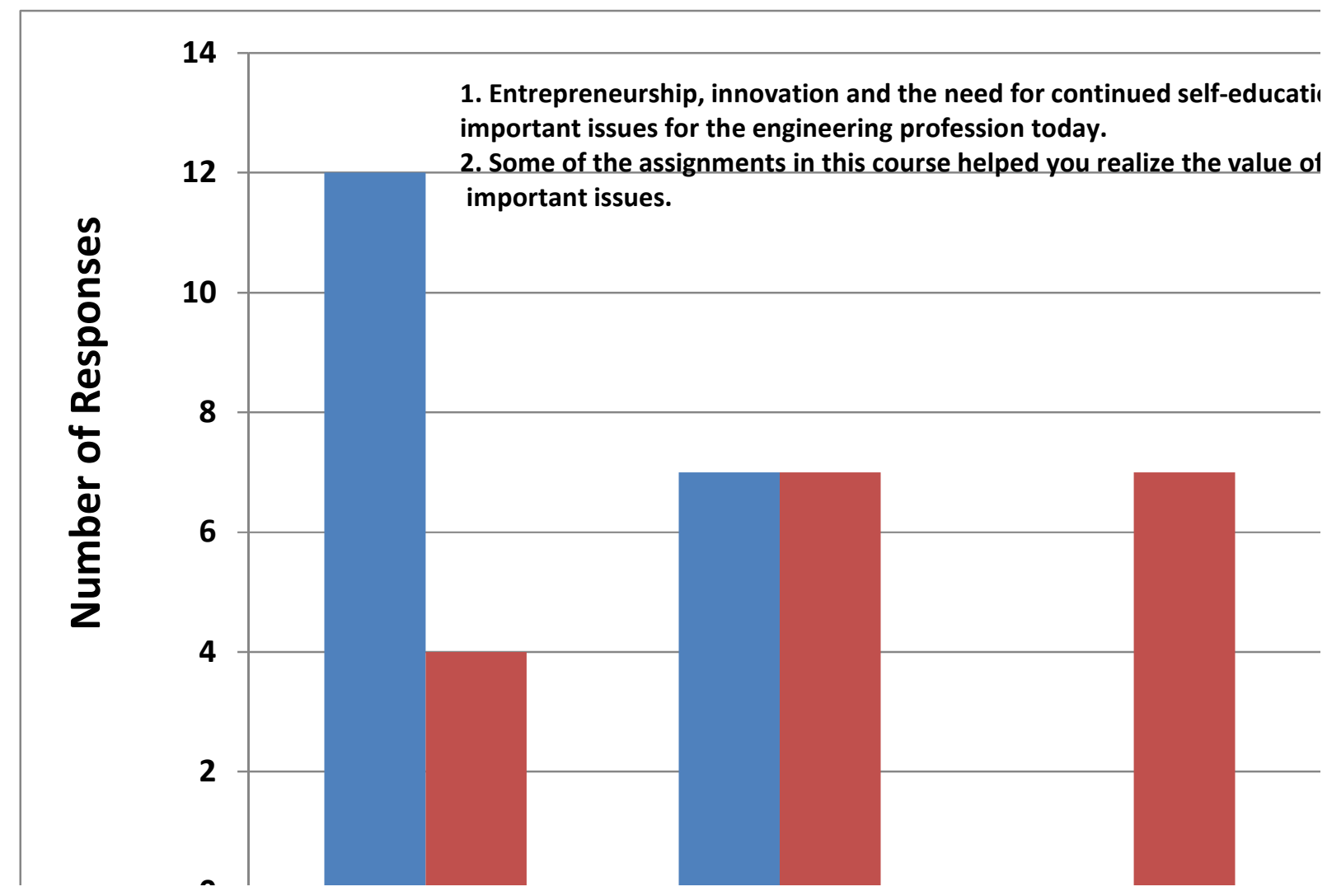

Figure 1. Responses to questions 1 and 2 of the survey:

Question 3 probed students' in a deeper manner by asking the students about the very nature of entrepreneurial mindedness. All students displayed a very good understanding of this nature, with a great majority (90\%) of them showing this level of understanding. This can further support the fact that students did indeed gain awareness of the importance of entrepreneurship, as was indicated by the responses to questions 1 and 2 above. 


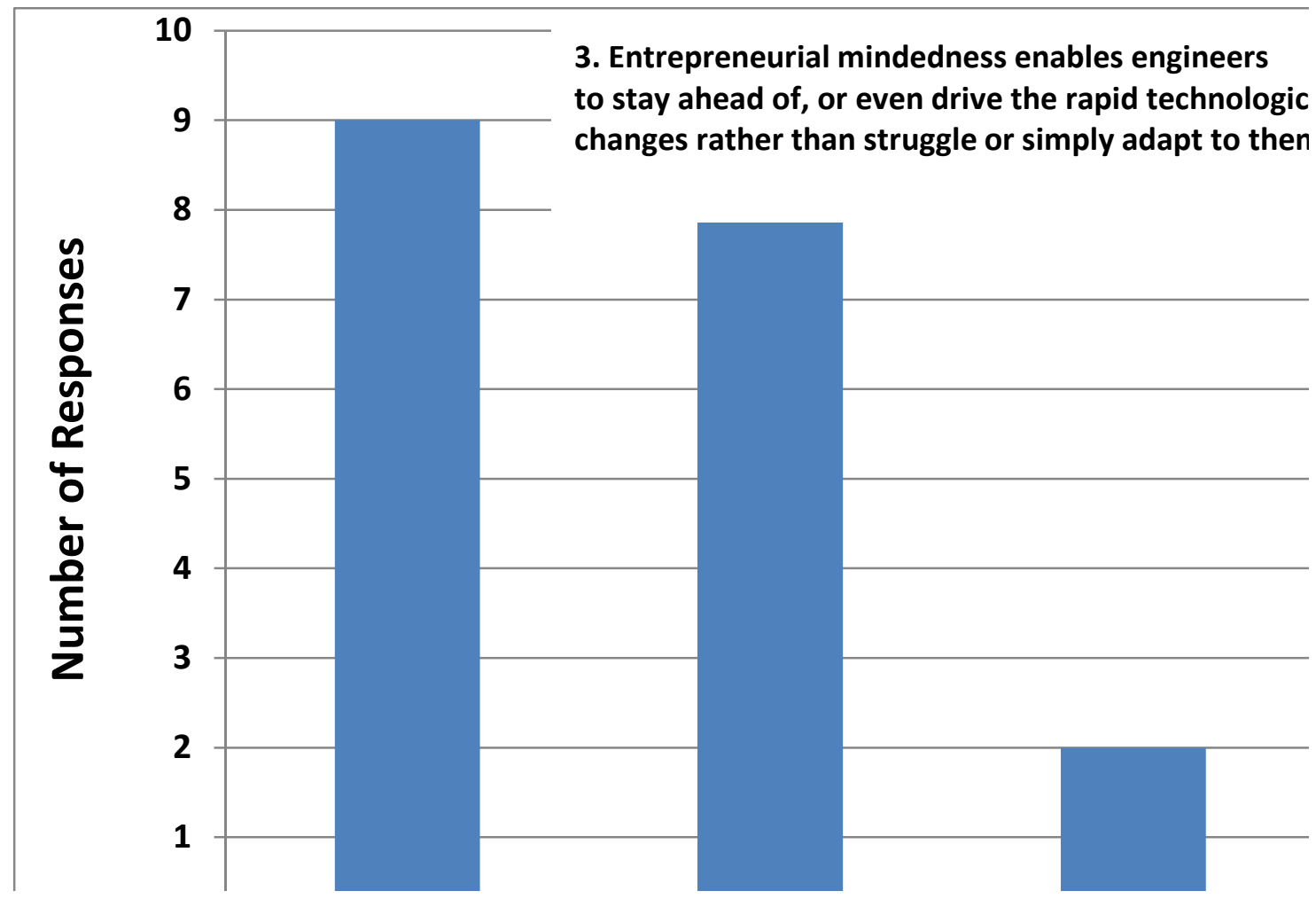

Figure 2. Responses to question 3 of the survey

Question 4 probed students' understanding of entrepreneurial ideas within a corporation. This requires an understanding of how corporations function and knowledge of busniess processes. All students indicated awareness of these issues, as indicated by the positive answers to questions 4 displayed the blue columns of Fig. 3. More importantly, all the students agreed that the course content helped them in becoming aware of these issues, as indicated by their responses to question 5. Figure 3 shows that $70 \%$ of the students confirming this with a strongly-agree or agree responses, while the remaining $30 \%$ slightly agreeing that the course helped them in this regard. 


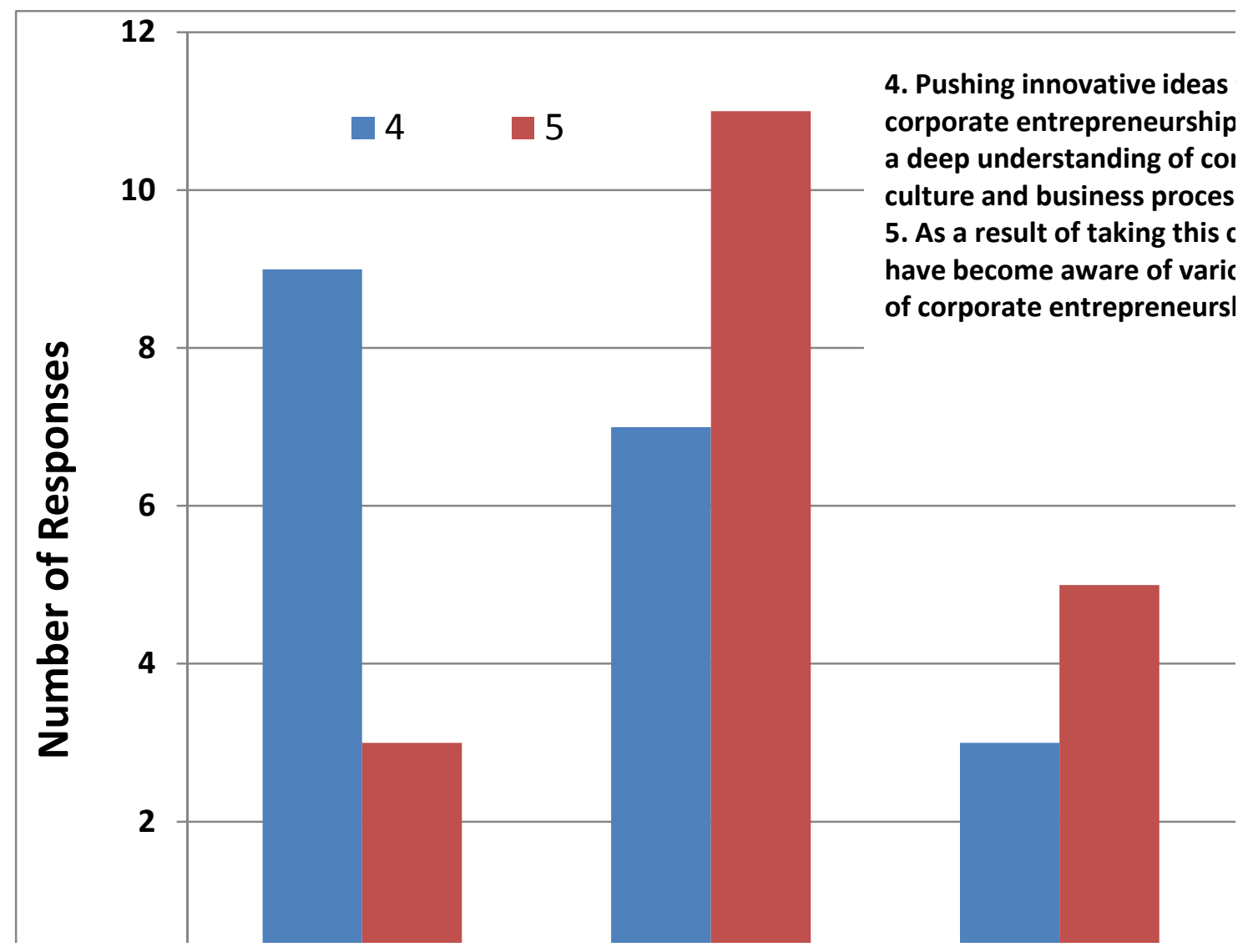

Figure 3. Responses to questions 4 and 5 of the survey

Question 6 probed students' knowledge and awarness of entreprenueral businesss models of social entrraprenuership as an alternative, when the government and th eproveat sector do not step in to solve some exisiting problems in society. All students exhibited an understanding of social entreprenuership as in dicated by the blue columns of Fig. 4. The course's effect on their awarness was assessed by question 7. All students felt that the course materials helped them in bringing about this awareness, with 14 students strongly agreeing or agreeing and 5 students slightly agreeing (red columns). 


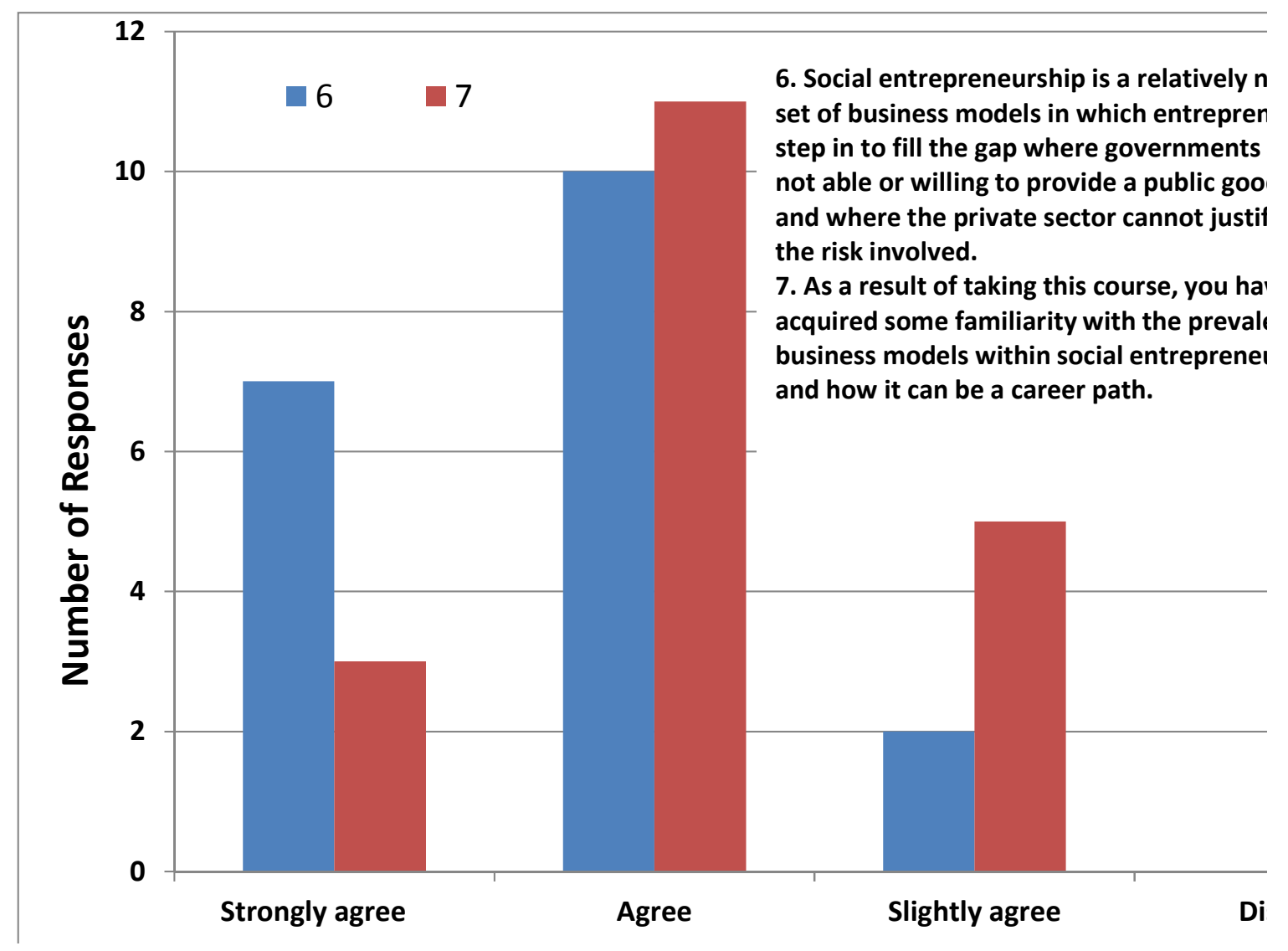

Figure 4. Responses to questions 6 and 7 of the survey

Questions 8 through 10 probed students in a couple of areas that are considered enabling for entrepreneurship activities. Questions 8 and 9 probed students' awareness of the importance of knowledge of oneself as it related to one's work environment, to the success of today's engineers. The responses to these questions are displayed in Fig. 5. All students agreed that this kind of knowledge is necessary for success in today's professional work environment. A good percentage $(73 \%)$ of students either strongly agreed or agreed that the course materials helped them in realizing the importance of self-knowledge. Only two students indicated that the course did not help them realize the value of these important issues. 


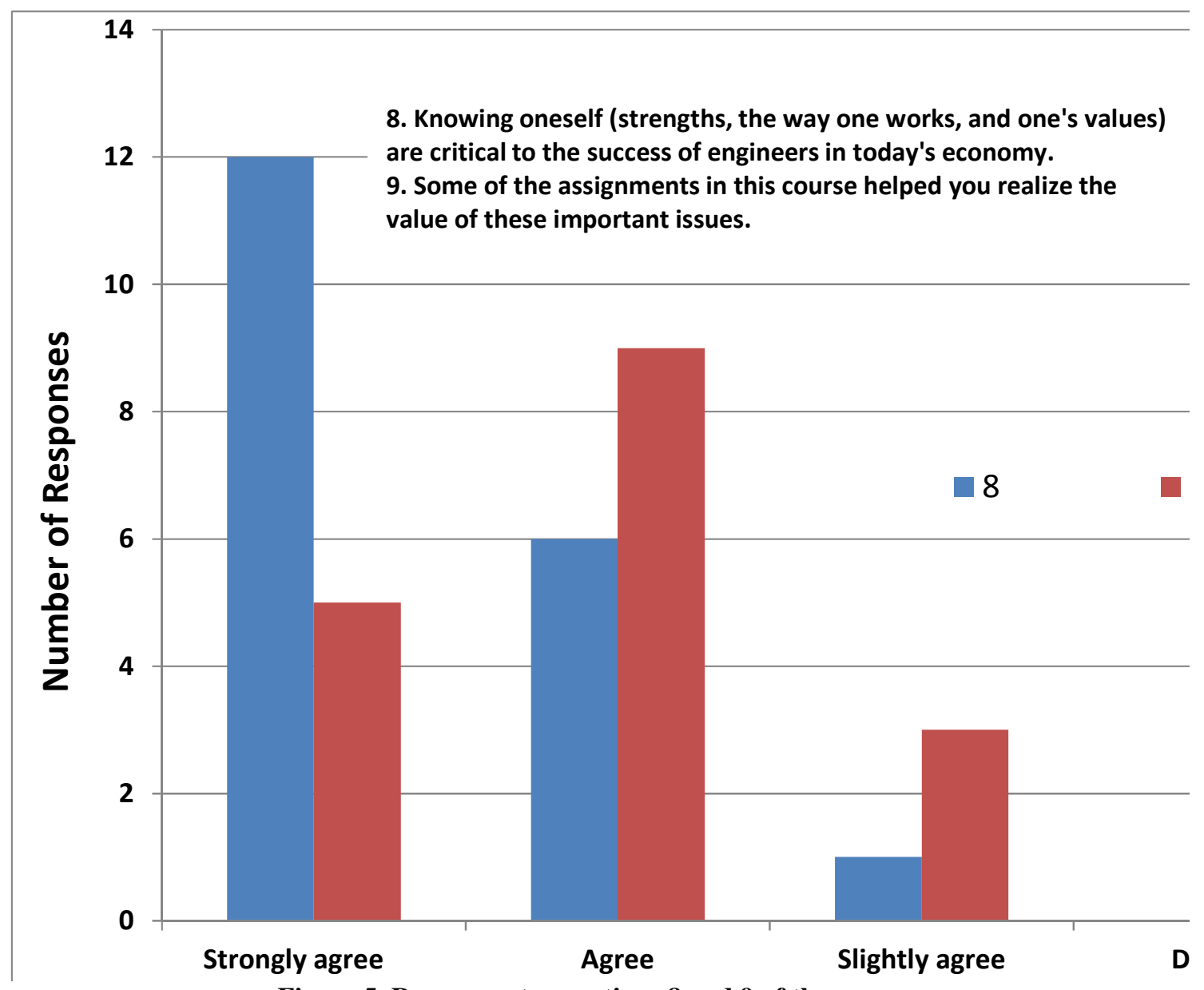

Figure 5. Responses to questions 8 and 9 of the survey

Question 10 probed students' understanding the inevitability of working with other people, and what it takes to work well with other people in a team. As seen in Fig. 6, all students exhibited this understanding, with a majority of $84 \%$ agreeing or strongly agreeing to the statement of question 8. Here the authors argue that for one to work well with other people, one must first understand other people's performance modes, their strength and weaknesses and their values. 


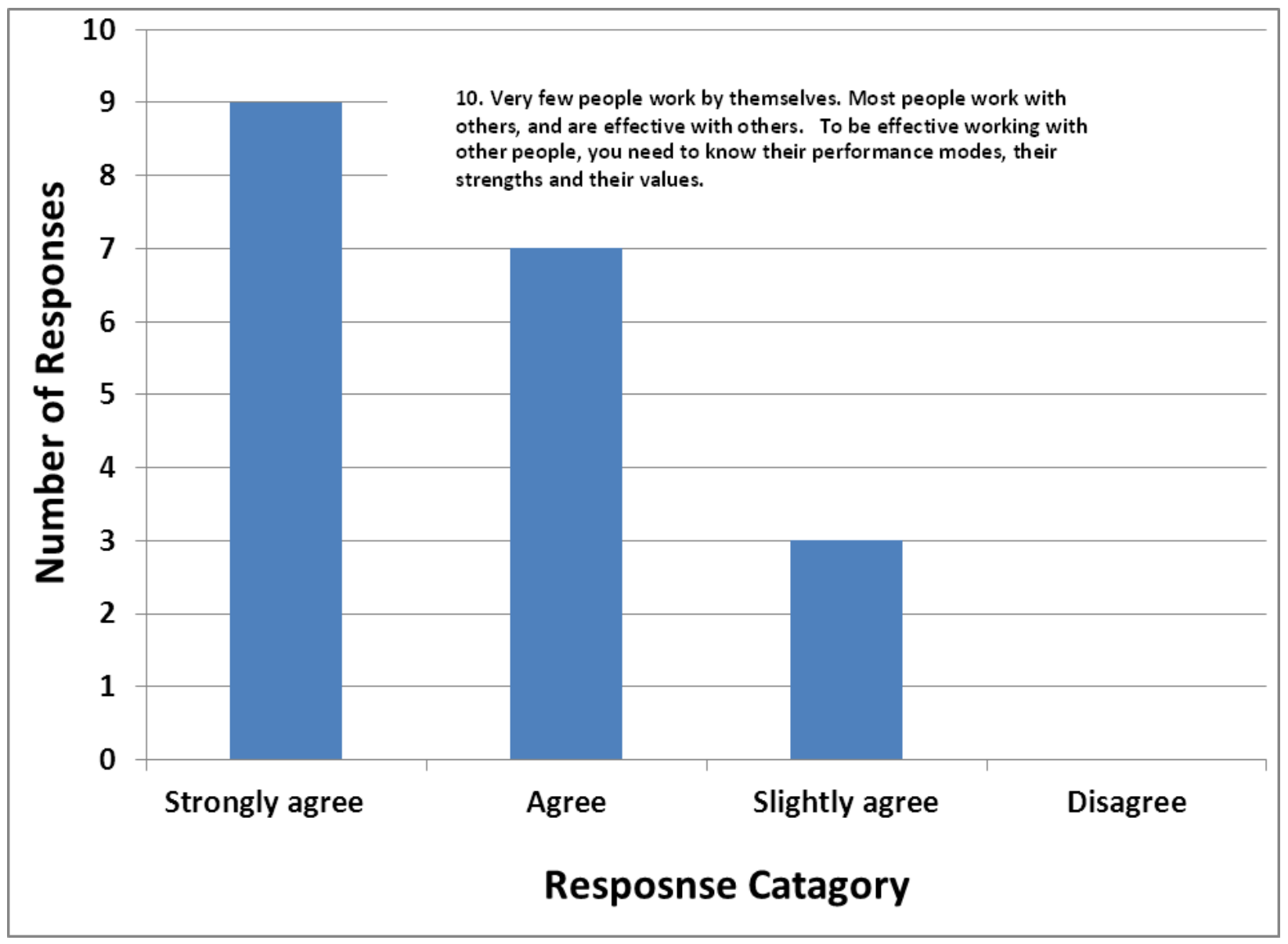

Figure 6. Responses to question 10 of the survey

\section{Conclusion}

The importance and description of innovation, entrepreneurship and life-long learning, as well as a couple more non-technical skills for graduating engineers was outlined, especially in light of the nature of the current knowledge-based economy and the problems that the world is facing. Some of the discourse of several engineering, governmental and educational organizations as well as the industry regarding these issues has also been summarized. A specially designed course for surgically teaching these skills in a US university was described in some detail. Course content, delivery and outcomes were given. After taking this course, students responded to a questionnaire as a way of propping their learning gains and the effect the course had on bringing about awareness of the above skills and issues. Students' awareness was enhanced in the following areas: entrepreneurship, innovation, continued self-education, self-awareness in a professional environment and working in teams. Students' responses in class discussions and their performance in quizzes indicated that they have learned the targeted skills and that the course was effective in helping them acquire the awareness of these issues.

\section{Acknowledgment}

The authors wish to acknowledge the support of the Kern Family Foundation through the Kern Entrepreneurship Education Network. 


\section{Bibliography}

1. Palmer, B., Terenzini, P., McKenna, A., et al., "Design Context: Where do the Engineers of 2020 Learn This Skill?" Proceeding, ASEE Annual Conference and Exposition, Vancouver, BC, Canada, June 26-29, 2011.

2. ___ The Accreditation Board for Engineering and Technology (ABET): www.abet.org, acceded June 30, 2012.

3. Shuman, L. J., Besterfield-Sacre, M. and McGoury, J., "The ABET "Professional Skills"- Can They Be Taught?

Can They Be Assessed?” Journal of Engineering Education, Vol. 94, No. 4, January 2005, pp. 41-55.

4. ___ The National Academy of Engineering, "The Engineer of 2020: Visions of Engineering in the New

Century," National Academic P, Washington D.C., 2004.

5. ___ News and Notes, "National Academies Issue Report on U.S. Innovation,” Mechanical Engineering, Vol. 134, No. 11, Nov. 2012, pp. 10.

6. Lord, M., “The Right Kind of Innovation,” Prism, Vol. 2, No. 9, Summer 2012, pp. 49.

7. Graham, R., “The One Less Traveled by: the Road to Change in Engineering Education," Journal of Engineering Education, Vol. 101, No. 4, October 2012.

8. Jawaharlal, M., Fan, U.-J. and Monemi, S., "Implementing Service-Learning in Engineering Curriculum," Proceedings, ASEE Annual Conference \& Exposition, Chicago, IL, Paper 2614, June 2006.

9. Kirpatrick, A., "Reduction to Practice," Mechanical Engineering, Vol. 134, No. 11, November 2012, pp. 38-39. 10. N. Dukhan, M. Schumack and J. Daniels, "Implementation of a Service-Learning Component in Engineering and Its Effect on Students' Attitudes and Identity,” European Journal of Engineering Education, Vol. 33, No. 1, March 2008, pp. 21-31.

11. Lathem, S. A., Neumann, M. D. and Hayden, N., "The Socially Responsible Engineer: Assessing Student Attitudes of Roles and Responsibilities," Journal of Engineering Education, Vol. 100, No. 3, July 2011, pp. $444-474$. 12. Drucker, P. F., Managing Oneself, Harvard Business Review, 1999: on-line www.hbr.org, accessed June 4, 2012.

13. Elkington, J. and P. Hartigan, "Creating Successful Business Models: Lessons from Social entrepreneurship, Harvard Business Review, 2008: on-line www.hbr.org , accessed June 4, 2012. 